\title{
USO DO LABORATÓRIO DE INFORMÁTICA NO ENSINO DE CIÊNCIAS
}

\section{Luan de Oliveira Cerqueira ${ }^{1}$ \\ Quezia Pains Dutra² \\ Laís Amorim ${ }^{3}$ \\ Érica Amorim Shwan Frade ${ }^{4}$ \\ Anderson Lopes Peçanha ${ }^{5}$}

Resumo: Um dos papeis do professor é modificar seu método de ensino, além de fazer do próprio aluno sujeito ativo no processo de ensino-aprendizagem. As diferentes modalidades didáticas, como aula expositiva, aula prática, seminários e o desenvolvimento de projetos, são usadas para diminuir o desinteresse dos alunos e facilitar o processo de ensino. Visto isso, este trabalho desenvolveu um trabalho prático do conteúdo de Alimentos e Sistema Digestório utilizando o laboratório de informática da escola com duas turmas de $8^{\circ}$ ano do Ensino Fundamental. As duas turmas tiveram aula teórica dos conteúdos e foram levadas ao laboratório de informática, onde tiveram acesso à internet e ao programa Microsoft Office Word para confeccionarem um folder informativo sobre Distúrbios Alimentares comuns que afetam a sociedade. A atividade mostrou-se eficaz e supriu a carência de ferramentas didáticas na escola além de complementar o estudo do conteúdo.

Palavras-chave: Folder; Ferramenta didática; Alimentos.

\footnotetext{
${ }^{1}$ Ciências Biológicas Licenciatura/Universidade Federal do Espirito Santo, Brasil. E-mail: luaano@hotmail.com. 2 Ciências Biológicas Licenciatura/Universidade Federal do Espirito Santo, Brasil. E-mail: quezia_dutra@hotmail.com.

3 Ciências Biológicas Licenciatura/Universidade Federal do Espirito Santo, Brasil. E-mail: laisguvi@hotmail.com.

4 Docente/Escola Estadual de Ensino Fundamental e Médio Aristeu Aguiar, Brasil. E-mail: easfrade@hotmail.com.

5 Docente /Ciências Biológicas / Departamento de Biologia / Universidade Federal do Espirito Santo, Brasil. Email: lopes.pecanha@gmail.com.
} 